\title{
Role of Self-Measured Home Blood Pressure Monitoring (HBPM) and Effectiveness of Telemedicine During the Era of COVID-19 Pandemic
}

\author{
Kamal Sharma ${ }^{1} \cdot$ Hardik D. Desai $^{2}$ (D) \\ Accepted: 4 March 2021 / Published online: 10 March 2021 \\ (C) The Author(s), under exclusive licence to Springer Nature Switzerland AG 2021
}

Letter to Editor,

Hypertension is one of the important risk factors for both disease burden and death of coronary diseases worldwide, and this risk can be mitigated by the medical management of hypertension [1]. It is also a significant burden for cerebrovascular disease [2]. Hypertension treatment is still among the most frequent factors in adults worldwide for outpatient visits to doctors' clinics [3]. Even prior to coronavirus disease 2019 (COVID-19), self-measured home-blood pressure monitoring was important, and even more so now to keep blood pressure under control just as managing blood pressure levels is becoming even more important with COVID-19. Reports suggest higher morbidity and mortality rates in COVID-19 patients with a history of hypertension among those affected by COVID-19 [4]. In the UK, overall consultation rates fell by about 30 percent shortly after lockdown compared to the previous years [5]. The assessment of blood pressure in everyday life is far from satisfactory, a condition made worse by the COVID-19 pandemic. Except under normal conditions, according to current standards, BP measurements in the office are not normally carried out. Over the COVID-19 pandemic, this condition deteriorated drastically, leading to challenges in accessing healthcare services and the massive workload placed on health care practitioners. In this sense, useful solutions have been provided by the use of home BP tracking,

This article is part of the Topical Collection on Covid-19

Hardik D. Desai

Hardikdesai198@yahoo.com

Kamal Sharma

drkamalsharma@unmicrc.org

1 Department of Cardiology, UN Mehta Institute of Cardiology and Research Center, BJMC, Ahmedabad, India

2 Graduate Medical Education, Gujarat Adani Institute of Medical Sciences, Affiliated to K.S.K.V University, Bhuj 370001, Gujarat, India better when paired with digital health technology facilitating remote telemonitoring of self-measured BP values. Delays in the follow-up and intensification of treatment beyond 6 weeks increase cardiovascular disease (CVD) events and are worse for those with higher blood pressure, especially SBP $>150 \mathrm{mmHg}$ [6]. For the diagnosis and treatment of hypertension, the validation and accuracy of an effective BP monitoring device are fundamental. Searching for an online registry is the best way to verify if a BP monitor is validated for accuracy. Users need, however, to know the characteristics of such registries and how to select the most suitable one. Indeed, there are many registries that monitor the validity status of BP monitors operated by reputable country-specific and international organizations [7]. Statistically, self-monitored BP at home is a significant indicator of potential cardiovascular risk than a manual assessment of BP at the workplace [8]. Selfmonitoring is an easy way to improve BP control as part of a self-management approach [9]. However, there is uncertainty in the schedule of self-measurement of BP. The American Heart Association and the American Society of Hypertension, along with the European Society of Hypertension and National Institute for Health and Care Excellence (NICE), suggest that BP must be monitored twice-daily with two measurements in the morning and two in the evening and 7 consecutive days, ideally in the morning and evening, with 2 per-occasion measurements taken 1-2 min apart [10-12]. New evidence has emerged that in the telemonitoring and/or self-monitoring of hypertensive blood pressure (TASMINH4) trial, the physician titration using patient self-monitoring resulted in lower BP and that using telemonitoring resulted in near goal BP quicker than selfmonitoring alone [9]. Furthermore, a study done by Macmanus et al. has reported that by using self-monitored blood pressure, the home BP digital intervention for the treatment of hypertension led to improved systolic blood pressure regulation as compared to the usual care beyond one year [13]. Furthermore, the meta-analysis of 18 randomized controlled 
trial have shown that the HBPM results in improved regulation of blood pressure and greater achievement of blood pressure targets than the usual monitoring of blood pressure in the healthcare system [14]. Out-of-office BP measurements have distinct advantages in certain subgroups, viz., identifying such pathological BP phenotypes, including white coat hypertension $(\mathrm{WCH})$ and masked hypertension $(\mathrm{MH})$; greater estimation of the prognosis of target organ injury and mortality; improved monitoring of BP; and checking for hypotension and providing a novel approach to the detection of circadian BP trends and variability of BP [15]. Telemedicine, and in particular, of HBPT can help patients in need of continuous monitoring of multiple vital signs and tight regulation of BP, such as high-risk patients with chronic diseases (ischemic cardiac disease or heart failure, diabetes, etc.), as well as nonadherent patients. Telemedicine is flourishing and evolving internationally in the ongoing pandemic as an invaluable resource for enhancing patient surveillance, containing disease transmission, encouraging early identification and timely treatment of infectious persons, and maintaining quality of care for elderly patients with numerous chronic conditions such as hypertension, heart disease, COPD, and diabetes. Studies have reported that telemedicine has significant effects in those who have higher BP, obese, previous stroke, diabetes, ethnic races, and blacks (medically underserved areas) while non-significant in patients with coronary artery disease and CKD, and pregnant women [16]. Remote tracking and transmission of vital signs (notably blood pressure) and adherence to medication, plus education on diet and risk factors, with video consultation as an alternative, may be the best possible healthcare model for telemedicine in hypertension treatment. In the long run, telemedicine can be an efficient, time and costeffective solution to treating hypertensive patients with HBPM as an effective method for managing hypertension.

Code Availability Not applicable

Authors' Contribution Dr. Hardik Desai designed the study and helped in writing the manuscript. Dr. Kamal Sharma contributed in manuscript writing.

Data Availability Not applicable

\section{Declarations}

Ethics Approval Not applicable

Consent to Participate Not Applicable

Consent for Publication Not applicable

Disclosure None

Conflict of Interest The authors declare no competing interests.

\section{References}

1. Lim SS, Vos T, Flaxman AD, Danaei G, Shibuya K, Adair-Rohani $\mathrm{H}$, et al. A comparative risk assessment of burden of disease and injury attributable to 67 risk factors and risk factor clusters in 21 regions, 1990-2010: a systematic analysis for the Global Burden of Disease Study 2010. Lancet. 2012;380:2224-60.

2. Perkovic V, Huxley R, Wu Y, Prabhakaran D, MacMahon S. The burden of blood pressure-related disease: a neglected priority for global health. Hypertension. 2007;50(6):991-7. https://doi.org/10. 1161/HYPERTENSIONAHA.107.095497.

3. National Institute for Health and Clinical Excellence. Hypertension: clinical management of primary hypertension in adults: CG127. NICE, 2011.

4. e Almeida-Pititto B, Dualib PM, Zajdenverg L, et al. Severity and mortality of COVID 19 in patients with diabetes, hypertension and cardiovascular disease: a meta-analysis. Diabetol Metab Syndr. 2020;12:75. https://doi.org/10.1186/s13098-020-00586-4.

5. Use of primary care during COVID-19 pandemic. Accessed on $1 \mathrm{st}$ February 1, 2021. [Available from: https://www.health.org.uk/ news-and-comment/charts-and-infographics/use-of-primary-careduring-the-covid-19-pandemic]

6. Xu W, Goldberg Saveli I, Maria S, Alexander T. Optimal systolic blood pressure target, time to intensification, and time to follow-up in treatment of hypertension: population based retrospective cohort study. BMJ. 2015;350:h158.

7. Picone DS, Padwal R, Campbell NRC, Boutouyrie P, Brady TM, Olsen $\mathrm{MH}$, et al. How to check whether a blood pressure monitor has been properly validated for accuracy. J Clin Hypertens (Greenwich). 2020;22(12):2167-74. https://doi.org/10.1111/jch. 14065.

8. Stergiou GS, Siontis KC, Ioannidis JP. Home blood pressure as a cardiovascular outcome predictor: it's time to take this method seriously. Hypertension. 2010;55(6):1301-3. https://doi.org/10.1161/ HYPERTENSIONAHA.110.150771.

9. Mc Manus RJ, Mant J, Franssen M, Nickless A, Schwartz C, Hodgkinson J, et al. Efficacy of self-monitored blood pressure, with or without telemonitoring, for titration of antihypertensive medication (TASMINH4): an unmasked randomised controlled trial. Lancet. 2018;391(10124):949-59. https://doi.org/10.1016/S01406736(18)30309-X.

10. Excellence NIfC. Hypertension: management of hypertension in adults in primary care. http://www.nice.org.uk/guidance/CG127/ NICEGuidance; 2011. Report No: Clinical Guideline 127.

11. Mancia G, Fagard R, Narkiewicz K, Redón J, Zanchetti A, Böhm $\mathrm{M}$, et al. $2013 \mathrm{ESH} / \mathrm{ESC}$ Guidelines for the management of arterial hypertension: the Task Force for the management of arterial hypertension of the European Society of Hypertension (ESH) and of the European Society of Cardiology (ESC). J Hypertens. 2013;31: 1281-357.

12. Pickering TG, Miller NH, Ogedegbe G, Krakoff LR, Artinian NT, Goff D, et al. Call to action on use and reimbursement for home blood pressure monitoring: a joint scientific statement from the American Heart Association, American Society of Hypertension, and Preventive Cardiovascular Nurses Association. Hypertension. 2008;52:10-29.

13. McManus Richard J, Paul L, Beth S, Katherine M, James R, Jo K, et al. Home and Online Management and Evaluation of Blood Pressure (HOME BP) using a digital intervention in poorly controlled hypertension: randomised controlled trial. BMJ. 2021;372: $\mathrm{m} 4858$.

14. Cappuccio FP, Kerry SM, Forbes L, Donald A. Blood pressure control by home monitoring: meta-analysis of randomised trials. BMJ. 2004;329(7458):145. https://doi.org/10.1136/bmj.38121. 684410.AE Erratum in: BMJ. 2004 Aug 28;329(7464):499. 
15. Zhu H, Zheng H, Liu X, Mai W, Huang Y. Clinical applications for out-of-office blood pressure monitoring. Ther Adv Chronic Dis. 2020;11:2040622320901660. https://doi.org/10.1177/ 2040622320901660.

16. Omboni S, McManus RJ, Bosworth HB, Chappell LC, Green BB, Kario K, et al. Evidence and recommendations on the use of telemedicine for the management of arterial hypertension: an international expert position paper. Hypertension. 2020;76(5): 1368-83. https://doi.org/10.1161/HYPERTENSIONAHA.120. 15873.

Publisher's Note Springer Nature remains neutral with regard to jurisdictional claims in published maps and institutional affiliations. 